Research Article

Open Access

\title{
Psycho-Social Traumatic Events among Women in Nigeria
}

\author{
Ruth Abiola Adimula ${ }^{1}$ and Ignatius Nnamdi Ijere ${ }^{2 *}$ \\ ${ }^{\prime}$ Lawyer, Lecturer, Centre for Peace and Strategic Studies, University of Ilorin, Ilorin, Nigeria \\ ${ }^{2}$ Associate Teaching Professor, Department of Public Health Syracuse University, New York, USA
}

\section{Article Info}

\author{
*Corresponding author: \\ Ignatius Nnamdi ljere \\ Associate Teaching Professor \\ Syracuse University \\ New York \\ USA \\ E-mail: inijere@syr.edu
}

Received: April 4, 2018

Accepted: April 9, 2018

Published: April 16, 2018

Citation: Adimula RA, ljere IN. Psycho-Social Traumatic Events among Women in Nigeria. Madridge J AIDS. 2018; 2(1): 17-28. doi: $10.18689 / \mathrm{mja}-1000104$

Copyright: (c) 2018 The Author(s). This work is licensed under a Creative Commons Attribution 4.0 International License, which permits unrestricted use, distribution, and reproduction in any medium, provided the original work is properly cited.

Published by Madridge Publishers

\begin{abstract}
This article reviewed literature and scholarly studies related to psychosocial traumatic events among women in Nigeria. It conceptualized and discussed trauma from universal and cultural perspectives and different types of trauma. Taking Nigeria a context, this article reviewed different types of Traumatic events experienced by Nigerian women; identified the effects of Traumatic events on Nigerian women. Finally, this article provided possible solutions to reduce trauma against women and its psychosocial impacts.
\end{abstract}

Keywords: Psychosocial; Trauma; Culture; Polygamy; Fertility; Social culture, \& poverty.

\section{Introduction}

Traumatic events are sustained psychological experiences that tend to significantly impairs a person's daily functions and is identified by symptoms constellations that are contained in the International Classification of Diseases (9 ICD-2010) or the Diagnostic and Statistical Manual of Mental Health $5^{\text {th }}$ edition (DSM-V-TR). While there are crosscultural communities in symptoms of traumatic events, non-western cultures have identified various symptoms and event-related triggers of traumatic experiences not included in DSM-V and ICD. Thus, the risk of experiencing traumatic events among Nigerian women has been demonstrated. Therefore, Nigerian women are not exception to the epidemic experience of traumatic events.

Trauma is a psychological disordered resulting from severe mental or emotional stress or physical injury (Merriam-Webster Dictionary). It is a very difficult or unpleasant experience that causes someone to have mental or emotional problems usually for a long time. Women in a patriarchal society like Nigeria, are treated with gender subordination which subjects them to experiencing indelible traumas. Trauma, however is today regarded as one of the leading causes of death. As such, its theorist put to light its various sources as: intimate partner violence, natural disasters, loss of loved one, sexual assault or any physical or mental wound, rape, female genital mutilation and witness of violence. Poverty is yet another great cause of trauma amongst many Nigerian women, especially among the no/low income socioeconomic status, polygamy is as well seen to be a great causative agent of psychological disturbances amid Nigerian women chiefly among the northerners, and of course the recent Boko Haram terrorist acts that subjected many Nigerians to psychological distortion [1]. Also, we cannot leave out one of the most reprehensive subjugation among the so called cultural practices in Nigeria which is the oppression borne out of widowhood. 
It is generally believed that trauma theory is an amalgam of psychological studies with that of humanities. All in all, women in Nigeria are exposed to the risk of getting traumatized through situations like; domestic violence, limited social or religious sanctions, lack of social support and most importantly, cultural norms. Oluwole DA [20] in a research article on Patterns of Stress, Social Support and Mental Health among Nigerian Women venerated on the issue of trauma faced by Nigerian Women as: "The effort to have and maintain a balanced mental health by the Nigerian women is thwarted by the presence of stress resulting from traumatic and rapid changes of life events". At this point, it is very important we conceptualize trauma in western and Nigerian context.

\section{Conceptualization of Trauma}

Before getting into cultural conceptualization of trauma, it is very important to conceptualize the term 'Trauma' from a historical point of view. Trauma as a concept is a derivative term/concept from Greek word that stands for "wound'. At the time of antiquity, there was no proper articulation of the term trauma. However, the birth of the late $19^{\text {th }}$ century Pierre Janet and Sigmund Freud presented the first approach toward the conceptualization of the concept. They also identified its characteristic features and some of the major clinical implications were identified. Furthermore in history, Pierre Janet and Sigmund Freud conceptualized a particular form of trauma-'psychological trauma'.

Although Freud's conceptualization of psychological trauma met with high level of criticism, the modern conceptualization of trauma would owe their origin to Freud's theory on trauma.

In the contemporary time, the term 'Trauma' could mean different things to different people and different situations. For instance, medical and behavioral scientists would conceptualization trauma different. For the medical professionals, trauma is related to events of life that are physical that are life-threatening due to accidents or physical injuries sustained due to car accidents or fall. This is a medical perspective has been adopted in USA. In the light of medical conceptualization of trauma, US Government views trauma as "an injury that results from exposure to either a mechanical force or another extrinsic agent, including an extrinsic agent that is thermal, electrical, chemical, or radioactive" [35]. However, behavioral scientists viewed trauma from a different perspective and conceptualized it as psychological experience. For them, trauma is the end product of negative psychological experience "from an event, series of events, or set of circumstances that is experienced by an individual as physically or emotionally harmful or life threatening and that has lasting adverse effects on the individual's functioning and mental, physical, social, emotional, or spiritual well-being" (Substance Abuse and Mental Health Services Administration [67].

There are two implications to be recognized on the behaviorist's conceptualization of trauma. First is that traumatic events inflicts horror, sense of helplessness, serious or threats of physical/psychological injury and /or death on the individuals who has a first-hand experience of the event. Secondly, that the impact of traumatic events goes beyond their direct victims to their indirect victims such as witnesses of the event, and rescue workers, friends/relatives of the first hand victims. In articulating psychological trauma, some scholars explained that psychological trauma are internal and emotional injury more immediately than it does a laceration or broken bone [73].

In a broader context, Diagnostic and Statistical Manual of Mental Disorders [7] clearly defined trauma as the "Exposure to actual or threatened death, serious injury, or sexual violence in one (or more) of the following ways: directly experiencing the traumatic event(s); witnessing, in person, the traumatic event(s) as it occurred to others; learning that the traumatic event(s) occurred to a close family member or close friend (in case of actual or threatened death of a family member or friend, the event(s) must have been violent or accidental); or experiencing repeated or extreme exposure to aversive details of the traumatic event(s) [p. 271].

As accurate this definition could be, it has met with several forms of criticisms in which critics have noted that actual or threat of the events does not need to occur before it could be conceptualized as traumatic events. Other critics insist that traumatic events are 'subjective' and argued that DSM 5 did not caption the relativity of traumatic events. This means, "A particular event may be experienced as traumatic for one individual and not for another" [67].

Critics of DSM's definition insist that there is need for any definition of trauma event to take into consideration the social, cultural and anthropological component of human existence. Nevertheless, the contextual conceptualization of traumatic events does not rule out the fact that "Trauma is a universal experience for people living across the globe. However, the way in which trauma is interpreted, as well as the effects of trauma on an individual, are all influenced by the cultural lens through which the person views the event" [15]. As a universal hostile human experience, traumatic events tend to inflicted plans unto their victims in several ways which include and not limited to the following: emotional and/or physical abuse by one's partner or family member; sexual assault of a child; purposeful, violent, nonsexual assailment by another person; rape; incest; loss of a family member to a violent act; critical harm or injury of a nonsexual nature to one's child by another person; and loss of personal assets and/or employment as a result of carelessness or brutality [17]. However, such hurtful experiences are mostly inflicted to individuals and thus, psychologists have suggested that these experiences be conceptualized and interpreted from the individual's cultural perspective.

This means that traumatic events though crosses cultural boundaries and context, its interpretation, prevention, treatment has to respect culture of the individual inflicted. Trauma therefore, has both universal and contextual 
connotation. It is this contextual connotation that gives meaning to the event and the individual inflicted; allows the victim to respond to the event, and sort out ways to reduce its impact on his or her daily life activities. This creates room for the discrepancies in the ways individuals responds and interprets traumatic events. These types discrepancies appear to be healthy in understanding traumatic events. Thus, some scholars affirmed, "Because culture is critical to the nature and development of the self, it also needs to become a critical issue in research in adjustment to trauma" [38]. This mean cultural contextual approach to traumatic event and its effects does not rule out the need to integrate global/universal component in the process. Rather, "It is important to take both aspects into account if one assumes that traumatic experiences must be integrated on both these levels in order to give those affected the best possible chance of survival in the future"[56]. While doing so, we still have to keep in mind the unique and similar impacts/effects of traumatic events on the victims. Such an approach can help towards gaining insight into the conceptualization of trauma in Nigerian context or culture and its psychological impacts as experienced by Nigerian women.

In an attempt to conceptualize trauma as experienced by Nigerian women, a Nigerian scholar [1] presented a long list of traumatic events in Nigeria experienced by women. She insisted that Nigerian women appear to be subjected to the following traumatic events: "female circumcision or in other words genital mutilation; a long known barbaric act of ritual; gender driven poverty; polygamy; work place sexual harassments; domestic violence, limited social or religious sanctions, lack of social support and most importantly, cultural norm and most recently the Boko Haram events [53]. Thus, some other Nigerian scholars have noted that these practices and traumatic events imposed on women have become barriers to the psychological well-being of Nigerian women thus, "The effort to have and maintain a balanced mental health by the Nigerian women is thwarted by the presence of stress resulting from traumatic and rapid changes of life events" [53].

It is important to note that some of these traumatic events are very humiliating and psychological hurtful to the victims and their families. For instance, "The trauma of being a widow is heightened, when the society tends to interfere in family matters, the shattering situations grow worse rather than better. In reality, a bereaved person on losing a spouse is actually at the weakest moment of one's life. At such a time the loss of a loved one, especially a spouse, surely leaves one with an emotional void and feelings of insecurity and pain seem to hit the survivor the most"[1]. Such an experience comes with emotional, cognitive and behavioral elements that are very harsh and they are being imposed by the society. It is a trauma imposed by the society in which "Widows are treated with harshness and cruelty; in some parts they are forced to drink the water used in bathing the corpse" [1]. Psychologists have categorized this type of traumatic experience as 'social trauma'.
Another example of social trauma experienced by Nigerian women is the 'wife rape'. This has gone unnoticed and not talked about openly in Nigerian society. Women are forced against their will to have sex with their husbands and sometimes are culturally forced to have sexual relationship with their immediate brother-in-laws in the event of their husband's death. The problem with either of the situations is that women are physically, emotionally forced; threatened into sexual activities. It is a serious problem and has constituted high rate of traumatic experience among Nigerian women. Thus, scholars have indicated that "Rape in marriage may well be the most common form of sexual assault, particularly if we consider that women who are involved in physically violent relationships may be especially vulnerable to being raped by their partners"[11]. Further, "Research indicates that between one third and one half of battered women are raped by their partners and that sexual abuse is characteristic of the most violent relationships" [11]. Wife rape has been classified as one of the social traumatic experience or event in many societies, especially in Nigerian society. Thus, it could therefore be implied that Nigerian women who have experienced 'wife rape' may have also experienced violent relationship, especially in the hands of their husbands. This suggests that wife rape, as a form of social trauma is characterized with violent attitude toward wives from their husbands who tend to display direct attitude of the society toward women.

It is also very common for many Nigerian women to experience other forms of social traumatic experiences and events, for instance cultural perception that women are properties to their fathers and husbands. This is because the general attitude and social outlook on women has been such where women have been seen as a property to their fathers and then, to their husbands. This horrible social attitude is reflected in many ways women have been treated in many parts of the Nigerian society Such harsh treatments include the following: not worth been educated; not qualified to own a land in their father's own, no right/ privileges in their father's home; not allowed to participate in village meetings of men; not allowed to present kola nut to male or female visitors in their homes, etc.

Furthermore, Nigerian scholars have identified emotional mishaps as another serious source of traumatic experience for Nigerian women. In describing this form of traumatic experience, a Nigerian scholar noted that "Every woman has a wish and a dream, and would feel thrilled when given the chance to make her dream come true or even at least, to fulfill her wishes"[1]. However, it is unfortunate that in a patriarchic society such as Nigeria, most women have been denied the ability to fulfill their political, social, economic and educational potentials. They have been "...deprived of the ability and sense of choice, they are reduced to an ordinary house wife not even a home maker, almost enslaved by her own husband, in her own legal matrimonial home" [1]. This have resulted too many Nigerian women experiencing a lot of traumatic repressed/blockade emotions [1]. 
In an attempt to define and explain emotional repression/ or blockade, some studies noted that "Emotional blockade is a condition exhibiting one or more of the following characteristics over a long period of time and to a marked degree that adversely affects the behavior and performance of individual: Inability to build or maintain satisfactory interpersonal relationships; Inability to act or react that cannot be explained by intellectual, sensory, or health factors; Inappropriate types of behavior or feelings under normal circumstances; a general pervasive mood of unhappiness or depression; a tendency to develop physical symptoms for psychosomatic disorders or fears associated with personal problems; Hyperactivity (short attention span, impulsiveness); Aggression/self-injurious behavior (acting out, fighting); Withdrawal (failure to initiate interaction with others; retreat from exchanges of social interaction, excessive fear or anxiety); Immaturity (inappropriate crying, temper tantrums, poor coping skills); Learning difficulties (academically performing below grade level) [58]. However, psychologists have suggested that such a traumatic experiences are very difficult to identify and treat. This is because, "Repressed emotions are easily mistaken for lack of emotion, hence masking their possible role in the etiology of poorly understood medical illnesses. Repression is particularly difficult to discern when related to past trauma or when constituting a lifelong emotional pattern without any identifiable "events."[43]. It is unfortunate that psychologists have not been able to discern symptoms of emotional repression traumatic experience within the Nigerian cultural context. This leaves the victims to the continuous pains associated with emotional repression traumatic experiences.

This section of the article has been able to conceptualize trauma from historical, universal, and Nigerian context. It has also briefly identified sources of these traumatic events and how they have been inflicted on Nigerian women. Unfortunately, some of these traumatic events have been supported by sociocultural environment. Such as support from the sociocultural environment tends to enhance the level or extent of the impact of these traumatic events. At this point, this article will articulate in details some of the areas of life Nigerian women have experienced trauma in Nigerian society.

\section{Areas of life where women experience trauma in Nigeria}

\section{Family}

In Nigeria, like in any other society, family is an integral part of the society, being a group of people who are closely related to one another by blood, marriage or adoption, which include both nuclear and extended family members. In the traditional lives of people in Nigeria, cultural norms are brought to play primarily in family and clan settings. Like in other African countries, issues of polygamy, infertility, male dominance and bearing many children are priorities, which many times bring trauma to affected women.

\section{Polygamy}

The practice of having multiple wives is very common among Nigerians, Africans and Muslims across the globe. In fact, Islam permit it and with the religious consent pocketed by the people in the society. Polygamy is a root cause of psychological disturbances among Nigerian women especially the northerners. Jealousy is indeed a natural instinct; rivalry is an off spring of accumulated jealousy and hatred. Hence, vicious acts against one another among the co-wives of the same husband seem to have inflicted the affected women whose husbands practice polygamy. These vices result in nothing but physical or mental torture of one another and traumatic situations inflict the existence of all involved. For example, in November 2017, Premium Times News reported the arrest of a 20-year-old housewife, Aisha Isah, in Yelwan-Bassa village, Kokona Local Government Area of Nasarawa state, for allegedly throwing into a well her two stepdaughters, Zainab 4, and Baaba 2, over disagreement with her co-wife. Aisha confessed to the crime and expressed remorse, claiming that the first wife was always instigating her children not to run errands for her, a development that infuriated her since she had no child of her own. There is no doubt that this type of incidence will continue to give traumatic experience to the co-wife whose children were murdered in cold blood in a polygamous marriage.

\section{Infertility}

Infertility refers to the inability of couples to achieve conception despite regular unprotected sexual intercourse for one year [69]. It also includes the inability to carry a pregnancy to the delivery of a live baby [78]. Even though infertility is not lethal, it has been described as a radical life changing problem that carries with it significant psychological trauma.

Infertility is a problem of global proportion. The World Health Organization (WHO) estimates that $8-12 \%$ of couples around the world experience difficulty conceiving a child. In Nigeria, prevalence rates may be higher. A recent study reported that up to a third of women in a rural community were affected, described as the most important reproductive health concern of Nigerian women, and accounts for between 60 and $70 \%$ of gynecological consultations in tertiary health institutions in Nigeria [50]. Illiteracy is rife in most communities in Northwestern Nigeria and as such, many notions exist as to the etiopathogenesis of infertility. Generally, the female is held responsible for virtually all cases of infertility with the men folk held as above board.

In most African societies, a passionate premium is placed on procreation in any family setting. In most cultures in Nigeria, the only proof of womanhood is motherhood and this makes infertile women experience both physical and psychological abuse. Earlier reports in Nigeria have documented psychosocial morbidity (marital instability, social ostracism, economic deprivation, depression, anxiety, suicidal ideation) associated with female infertility. Common psychological symptoms reported among infertile women include depression, anxiety, and suicidal ideation. 
Psychiatric morbidity is present in $46.4 \%$ of infertile women in southwestern Nigeria. Study has shown that high levels of psychological distress exist in patients with infertility. The prevalence of psychological distress in women attending infertility clinic in ABUTH is 37.8\% [50]. This is high when compared with finding from non-psychiatric units of general hospitals and community samples in Nigeria. The findings that infertility is associated with severe psychological distress are in agreement with previous studies [50].

Thus, it has been reported that Arogundade, a Catholic Bishop of Ondo has said that the trauma that couples, especially women, experience, is beyond expression. That married couples need more help in dealing with infertility and childlessness, which is one of the major causes of divorce in Africa. Highlighting that the increasing rate of infertility in Nigeria and other parts of Africa is alarming, while the complex process involved with adoption means it is not typically an option for poorer couples. He noted that the death of a childless person is like someone who never lived and that in a childless marriage, some men become careless with their married life, in the process of wanting to try something else, it leads to polygamy, adultery or other abuses in married life, while the women often are traumatized, praying every day to conceive a child [32].

\section{Male Dominance and urge for many children}

The role played by society in heightening women's traumatic experiences is apparent. Women are always deprived of the ability and sense of choice, she is reduced to an ordinary housewife not even a home maker, almost enslaved by her own husband, in her own legal matrimonial home. This is the height of masculinity and sense of dominance men exhibit in a patriarchal society like Nigeria. Many women are suffering from the trauma of repressed emotions. Just because a man is a chief and rich and powerful, has two or three female children, he is advised to take another wife not taking into consideration the feelings of the wife at home. The society believes that a man with great wealth and well positioned in the society should not have just two children. This belief contributes to the trauma. They push many women to him and try to kindle the desire of having an additional wife on him.

According to a Nigerian scholar, some women whose husbands are talked into marrying other wives because of their inability to reproduce is another side to the coin. Because of this threat, these women are compelled to endure the abusive nature of their husbands; they are automatically muted and deprived of wings to excel. They therefore have to play by the rule; otherwise, someone else would take over from where she has stopped [1].

"Where would I go if I leave his house? Tell me where would I go? ... Do you know how many mothers pushed their daughters at him? Do you know how many told him to impregnate them even, and not bother paying a bride price?"[1].
These types of question come to the minds of women going through situations like this. Society goes in supporting male dominance in a society like Nigeria to this extent. The society remains silent and no one complains about such outrageous practices. Women are thus traumatized not only due to direct attack from Men but also by the salient role the society plays in their marital life. The phallocentric notion that a woman must have many male sons in order to be valued culturally makes any woman to feel insecure.

Their very loving husbands beat some of these women to the state of miscarriages. Instead of questioning this cruel and violent behavior, the society blames the wife for not being able to give him as many children as he deserves. In this case, the woman's trauma becomes more vulnerable as the society is not in any way helpful [1].

\section{Domestic Violence}

The various forms of violence against women include wife battery, denial of self expression, female-child labour, childhood marriage, female genital mutilation, violence from in-laws, violence from sexual relationship, antagonism because of sex of new-born child, exploitation, violence by law enforcement agents, negative cultural attitudes and degrading traditional practices, e.g. widowhood rites and denial of female education [6].

Among victims who are still living with their perpetrators, high amount of stress, fear and anxiety are commonly reported. Depression is also common as victims are made to feel guilty fo 'provoking' the abuse and are frequently subject to intense criticism. It is reported that $60 \%$ of the victims meet the diagnostic criteria for depression, either during or after termination of the relationship and have a greatly increased risk of suicidality [8]. The most commonly referenced psychological effects of domestic violence is Post-Traumatic Stress Disorder (PSTD). According to some studies, PSTD (as experienced by victims) is characterized by flashbacks, intrusive images, exaggerated startle response, nightmares and avoidance of triggers that are associated with the abuse. Social support may have both a direct effect on mental health in the context of Intimate Partner Violence (IPV) and poor mental health outcomes. Similarly, tangible social support moderates the relationship between IPV \& PSTD [Posttraumatic Stress Disorder] symptoms. Many researchers state that PSTD is possibly the best diagnosis for those suffering from psychological effect of domestic violence, as it accounts for the variety of symptoms commonly experienced by victims of trauma. Major consequences of domestic violence victimizationinclude psychological/mental health, issues, and chronic physical health problems. A victim's overwhelming lack of resources can lead to homelessness and poverty [74].

In addition, it has reported that, depression, anxiety and Post-traumatic Stress Disorder are symptoms of domestic violence. Those Survivors of domestic violence are vulnerable to mental health disorders that are direct results 
of their victimization. Depression and severe anxiety are common problems for victims of battering relationships. These develop within the adverse conditions of violence and control, but can continue to be clinically significant when the relationship is over. Survivors may also develop Posttraumatic Stress Disorder, which is a persisting reaction to trauma. Many women will require mental health treatment for symptoms of such disorders along with counseling that deals specifically with domestic violence recovery. Victims of domestic violence are at risk for developing problematic substance use to cope with ongoing abuse as well as the after effects of abuse [25].

\section{Poverty}

It has been suggested by some Nigerian scholars that poverty appears to be one of the strongest risk factors for many Nigerian women. Thus, many Nigerian women below poverty level of income are at risk of developing financial traumatic symptoms. A woman can live through days without food, security or shelter but she cannot afford the same hardship if she has a child or children. The trauma of a woman is not only caused by what affects her directly but also more importantly by the lack faced by her children. Therefore, some Nigerian women like other impoverished women around the globe are traumatized by inadequate financial stability to make ends meet. This is more annoying to women whose husbands habitually derelict their duties [1].

\section{Socio-cultural}

\section{Widowhood}

One of the most reprehensive subjugation among the so called cultural practices is the oppression born out of widowhood. In Nigeria, the treatment is less intricate. She is not killed directly but indirectly; a widow suffers spiritual torture on the death of her husband, according to some old customs in certain parts of Nigeria. Her refusal to comply with these customs and heinous treatment would get her excommunicated from the society, for she is assumed to have committed a grievous sin. The trauma of being a widow is heightened, when the society tends to interfere in family matters. Many widows are suspected by family members of deceased spouse for been responsible for the death of the departed husbands [72]. When the death is sudden and without any sign of protracted illness. And to prove her innocence, the bereaved widow is subjected to all kinds of humiliations by the deceased's community.

In Nigerian society, widowhood is a dreadful experience. After the death of the husband, the widow is bound to experience different kinds of sufferings. These experiences however, differ from one culture to the other. In Igbo land for example, on the day of the deceased husband's burial ceremony, his elder sister (ada) washes the hands of the bereaved widow with water and rub them with an unbroken egg, which is thrown away into the bush. After this ritual, the widow goes into one month of seclusion without washing her body [3]. The widow is also required to perform purification and ablution rituals. He sewed a garment of fiber and shaves off her hair. At the end of one year of mourning, the widow discards the fiber garment and can re-marry if she so desired. This trauma sets the plight of widows in Igbo land on the litany of woes [72].

Amongst the Yorubas, a widow is believed to be the property of deceased husband and so she cannot inherit his property. Only children, brothers, and uncles are allowed to inherit the deceased persons' property. This exclusion of a bereaved widow in the issue of inheritance is also traumatic, to know that you are part of the inheritance to be shared, rather than being an inheritor.

Etsako people of Edo state consult the oracle after the death of the deceased husband and the widow is forced to swear at a shrine if she is accused of killing the deceased husband [5]. While the Esans subject the widow to different mistreatment. In most cases, the widow is forced to drink the water used in washing the legs of the deceased husband to prove her innocence. She mourns the husband for seven days in seclusion, eat from unwashed plates, run round the house or farm of the deceased's husband stark naked in broad day light and wear old clothes during mourning period. After the mourning period the widow is inherited either by the first son of the late husband if he was a polygamist or the brother-in-law if monogamist [72].

The Delta people, especially the Uhrobos, Isokos and Ndukwas inflict serious tortures on widow. The deceased's property is shared amongst the children and his brothers, while the widow is betrothed to another brother of the late husband [54]. However, if she objects to remarriage within the same family, then the widow is made to refund the bride price paid on her. The Ndokwa people, inquired into the death of a deceased husband, the widow is thrown over the coffin by some strong men up to seven times and if she happens to fall down in the process, it is believed that her hands were involved in the death of the husband.

The Yaba peoples whisk the widow from her late husband's house to the most elderly man within the family or clan during the mourning period. The widow is guarded by one of the sisters-in-law for forty days during which she is monitored to find out if she is pregnant [54]. The widow wore one dress throughout this period, bath in the presence of other widows, touch earthenware tripod and cook food for the whole villagers. After this ritual, the widow is allowed to re-marry within the family. But if she objects to the demand made of her, she is allowed to go empty handed [3].

These widowhood plights are usually traumatic, manifesting in diverse symptoms, some of which are that the bereaved widow expresses fearful anxiety which soon takes on the parlaying effects on the family, non-adjustment to stress results in illness that is benumbing, the weeping in bed and hospitalization becomes a daily occurrence, apathy and antipathy, not excluding illness of social collapse, are also noticed [71]. Psychologically too, back pain, muscles cramp, vomiting, lump throat, blurred vision, singing and 
whispering attitudes, abdomen emptiness, hair loss, tenor voice, day-night-rhythms, feeling of separation from the deceased husband, hallucinations, feelings of guilt, debility, heightened hostility towards other people and restlessness. Others are tension, jitteriness, hopelessness, persistent, watery eyes, melancholy attempt to commit suicide in order to terminate life and unusual pattern of speech when speaking about the deceased husband, are dominant features or symptoms expressed by the widow [59].

\section{Employment}

In contemporary times, in the corporate world, especially in the Banking sector, the purpose of recruitment of the female gender is to serve as marketing agents. These women are given unrealistic targets to meet. In a bid to meet the targets and particularly to keep their jobs, these women are consequently forced or led into prostitution with potential customers. This position dispassionately considered to make a woman lose her dignity on the platform of employment. In addition, in the Civil Service in Nigeria today, any woman married outside the husband's tribe may not be allowed promotion to some offices. For a woman with dreams and aspiration, this act can kill zeal and can lead to trauma in the sense that she is not living up to her own expectations.

\section{Educational institutions (especially young women)}

In educational institutions such in the universities, sexual harassment can be described as a gender-based discrimination, victimization or deprivation that is sufficiently serious. It interferes with or limits a student's ability to participate in or benefit from the institution's/university educational programs. It presents itself in power-based differentials (quid pro quo), which manifest in the creation of a hostile environment that breed retaliations and victimizations. Thus, studies have suggested that the interrelationships between sexual harassment and other issues are of major significance in the way that this practice in schools remains silenced and marginalized [60]. Sexual harassment in universities can be in three forms, namely; sexual harassment of a student by another student, sexual harassment of a faculty/staff member by a student, and sexual harassment of a student by a faculty/staff member (this is the more rampant and damaging form of harassment experienced in Nigerian universities [4].

Sexual harassment in educational environment according to studies affects negatively on the learners' right to equal educational opportunity and violates the victim's right to dignity, equality and bodily and psychological integrity. The consequences of sexual harassment are potentially very serious. It has been suggested that it can have destructive effects on individuals. An immediate concern is physical injury, which may be extensive enough to require medical treatment or hospitalization [22]. In addition, it has been suggested that sexual harassment creates emotional damage that may be serious and equally require treatment. Students who survive sexual assault and harassment from lecturers/university staff rarely perform at their prior academic levels, and are sometimes unable to carry a normal course load, and frequently miss classes. These changes sometimes stem from social withdrawal, and a desire to avoid the perpetrator. Assaulted students regularly drop courses altogether, leave school, or transfer [33]. In addition, it has been argued that along with decline in academic performance and social withdrawal, long-term outcomes may include increased risk of depression, substance abuse, self-harm, eating disorders, posttraumatic stress, personality disorders and suicide [24].

\section{Female Genital Mutilation (FGM)}

Another culturally controlled problem faced by women in some parts of Nigeria is female circumcision or in other words genital mutilation; a long known barbaric act of ritual. It has been reported that in the eastern part of Nigeria, and even some part of Africa like Egypt, females undergo circumcision to initiate or get them prepared for wifehood. Women who have undergone FGM may also be affected by chronic pain syndrome, and with other causes of chronic pain there is an increased risk of depressed mood, with reduced social functioning, worthlessness, guilt, and even suicidal ideation. Limited mobility also increases social isolation and role loss in society [77].

Further, some studies have suggested that women who have experienced FGM tend to develop psychological conditions, which make them withdrawn and uncommunicative or distrustful. There are anecdotal reports of teenage girls 'returning to the UK from "holidays" abroad who were well adjusted to school before they went, but who fail to thrive in the learning environment after they return' [14]. Other psychological effects include emotional distance, flashbacks, sleep disorders, social isolation, and somatization. A study in practicing African communities found that women who have undergone FGM have the same levels of Post-Traumatic Stress Disorder (PTSD) as adults who have been subjected to early childhood abuse, and that the majority of the women ( 80 per cent) suffer from affective (mood) or anxiety disorders [40].

It has also been found that the psychological trauma that women experience through FGM 'often stays with them for the rest of their lives' [27]. A study of a sample of newly married women in Benha city found that the psychological complications resulting from FGM 'may be submerged deep in the child's subconscious and may trigger behavioral disturbances' [26]. In addition, a Consultant Obstetrician from Oxford Rose Clinic mentioned a case of one of her patients who had undergone FGM about 30 years ago, but still recalls the trauma of the procedure $[18,75]$ examined the consequences of FGM and classified the women into three types:

The Adaptive: these women are overcoming the FGM experience and are able to talk about what bothers them. 
The Disempowered: these women feel angry and defeated, and do not talk about what was done to them, feeling ashamed, alone and disempowered.

The Traumatized: these women have suffered a lot of pain and sadness. They have recurrent memories, sleep problems and chronic stress; they feel misunderstood in their immediate environment and by health providers. These women may isolate themselves and experience a high incidence of anxiety/depression.

Therefore, it has suggested that it is important not to place women in a single category. Instead, women who have undergone FGM should be seen as individuals who have differing emotional and social needs [46].

\section{Boko Haram Insurgency/Displacement}

The most recent Boko Haram insurgency has subjected many Nigerian women to displacements, physical distortion and most of all psychological trauma. These women, as a result of series of terrorist attacks they encountered, lost their homes, jobs, children, husbands, relatives, loved ones etc. The trauma of witnessing such dreadful events is what some scholars described as extremely traumatizing. Female survivors of Boko Haram are immensely traumatized. Thus, according to the associated press of CTV News reported in the News article" Nigerian Women Rescued from Boko Haram Face Trauma and Stigma "that, the situation of women rescued from Boko Haram as "traumatizing and horrifying"[28]. This means that traumatic events can fundamentally change not only victims' way of life, but also their psychological outlook for people who has faced 'act of god' natural disasters and man-made catastrophes of terrorism and war. It has a range of different cognitive, emotional, physical, and behavioral effects on individuals. [12].

In a post election ethno-religious violent conflict victims IDP camp in Kaduna in April 2011, a study of the prevalence of PTSD, types of psycho-trauma experienced by the IDPS, factors associated with PTSD and their psychosocial adjustment was carried out among 258 respondents. It was found that, destruction of personal property, being evacuated from town, witnessing violence, reported death of a family member, and suffering ill health were the most frequent psycho-trauma experienced by the IDPs. [63].

In astudy among IDPs of Boko Haram insurgency in three camps in Abuja, Nigeria, viz: Oronzo, New Kuchingoro and Old Kuchingoro camps, it was found that their experience escaping the insurgency is a very traumatic one. The IDPs spoke of how a number of their family members were left behind and killed, some ran towards the Camerounian border while others ran up the mountains towards the Nigerian side of the border. Families were separated across two countries as a result. They stayed for days without food and were exposed to the elements. Finding showed that they were going through a lot of mental trauma. A chat with 8 boys aged 13-20 years and they spoke about how they have been abandoned by the government and exploited by employers in Abuja. A few of them are orphans left to fend for themselves. one 20-year old young man was quite emphatic that he would not go back home again, being the sole survivor of 11 family members after insurgents attacked his home, adding that he does not want anything to do with his village ever again [51].

A number of studies have also reported that women and girls were victims of physical and sexual violence in IDP camps $[8,66]$. Thus, women are at higher risk of unwanted pregnancies, unsafe abortions, maternal morbidity and mortality [9]. In addition, it has been reported that the IDPs in Boko Haram camps in Nigeria were experiencing "incidents of unwanted pregnancies, rape, child labor/ trafficking and sexually transmitted diseases [44]. "The negative impacts of sexual violence are significant and long term. These may include physical injuries, sexually transmitted infections including HIV, unwanted pregnancies and mental health effects [9].

Moreover, IDPs, particularly those affected by conflict, are at a high risk of mental health problems. The commonly reported psychological reactions are post-traumatic stress disorders (PTSDs) in reaction to violence, depression and loss (Getanda, Papadopoulos \& Evans). The psychological distress occurring in the post-conflict environment also contributes to harmful health behaviors such as hazardous drinking and increased smoking. These behaviors are linked to an increased burden of non-communicable diseases such as hypertension, chronic obstructive pulmonary disease and cancers (Saxon, Makhashvili, Chikovani, Seguin, McKee \& Patel). This article has so far demonstrated some of the areas where Nigerian women have experienced and continued to experience traumatic events. It is also important to review some of the risk and protective factors associated with Nigerian women's experience of traumatic events.

\section{Risk Factors and Protective Factors}

Risky behaviors have become a recent topic of concern in trauma and PTSD research, especially in the realm of behaviors associated with risky sexual practices, illicit drug use, and alcohol abuse due to possible risk of revictimization $[2,21,61]$. Regarding risk and protective factors of women, a study compared those with substance use disorders (SUD) and PTSD and those with just PTSD, and found that those with SUD/PTSD reported more victimization experiences. Saladin et al. suggest that this is due to greater exposure of traumatic events increasing coping via self-medicating which could lead to an SUD. Saladin and colleagues propose the inverse as well: that a pre-existing SUD could impair judgment, which in turn increases the exposure to risky situations that could lead to possible victimization. Their findings indicated that those with PTSD and SUD experience more arousal (in the form of sleep disturbances) and avoidance symptoms than those with PTSD alone [61]. Research has also shown that those who have experienced a traumatic event and that those trauma survivors who develop PTSD engage in more highrisk behaviors than those who have not experienced a 
trauma [19]. In a sample of crack/cocaine users in treatment, patients with PTSD exhibited overall greater levels of risktaking propensity than the non-PTSD group, even after controlling for other psychiatric disorders and psychotropic medication, [41].

The World Health Organization reported that immediate psychological trauma might stem from the pain, shock and the use of physical force by those performing FGM [78]. In the long term, post-traumatic stress disorder (PTSD), anxiety, depression and memory loss may occur [10].

\section{Risk and Protective Factors:}

Early aggressive behavior, undiagnosed mental health problems, drug availability, poverty, peer rejection, and child abuse or neglect are risk factors associated with increased likelihood of substance use and abuse.

Drug abuse begins and it progresses. Many factors can add to a person's risk for drug abuse. Risk factors can increase a person's chances for drug abuse, while protective factors can reduce the risk. Please note, however, that most individuals at risk for drug abuse do not start using drugs or become addicted. Also, a risk factor for one person may not be for another.

An important goal of prevention is to change the balance between risk and protective factors so that protective factors outweigh risk factors. Protective factors may lessen the likelihood of sexual violence victimization or perpetration by buffering against risk. These factors can exist at individual, relational, community, and societal levels. Research in this area is ongoing. The few protective factors identified by researchers to date are:

Parentaluse of reasoning to resolve family conflict.

Emotional health and connectedness.

Academic achievement.

Empathy and concern for how one's actions affect others ${ }^{1}$.

\section{Effects of traumatic experiences on women in Nigeria}

It is an over statement to say that the various traumatic events experienced by Nigerian women tend to occur independent of each other. In addition, it will be an over statement to indicate that experiencing one traumatic event does not trigger the vulnerability to other forms of traumatic experiences. The reality is that there is the possibility of Nigerian women experiencing two or more traumatic events at the same time. More also, it is possible that the experiencing of one traumatic event in the Nigerian culture will trigger the vulnerability of experiencing another form of traumatic event. This is particularly true for interpersonal, cultural and social traumatic events. Thus, some scholars stated that "a number of studies demonstrate that victims of interpersonal traumas are at statistically greater risk of additional interpersonal traumas. This is especially true in what is known as revictimization: those who have experienced childhood abuse are considerably more like to be victimized again as adults" [10]. This makes the identification of the effects of traumatic events and the development of clinical interventions/treatment very complicated. Thus, "this complicated mixture of multiple traumas and multiple symptomatic responses is well known to trauma-focused clinicians, who sometimes find it difficult to connect certain symptoms to certain traumas, and other symptoms to other traumas, or, in fact, to discriminate trauma-related symptoms from less trauma-specific symptoms"[10]. However, in the midst of this difficulty, clinicians have been able to identify some culturally bond effects of traumatic events among Nigerian women.

Several African scholars have presented techniques that can effectively measure the impacts of traumatic events on women. For instance, scholars have noted that, "The most common measurements of psychological distress in the aftermath or the midst of trauma are posttraumatic stress symptoms and posttraumatic stress disorder (PTSD)" [64]. Commonly reported posttraumatic stress symptoms include difficulty concentrating, irritability and outbursts of anger, intrusive thoughts, nightmares, and hyper vigilance. These symptoms appear to be shared by Nigerian women as sharing almost the same cultural risk factors like other African women. However, some Nigerian scholars have suggested that the exposures to interpersonal traumatic events are more likely to trigger the development of PTSD symptoms than natural disaster related traumatic events [52]. In addition, it has also been suggested, "the prevalence of PTSD may be expected to decline if there are no more exposures to violent events or trauma" [52]. In another research, it has been suggested that offspring's of individuals who have experienced traumatic events are at high risk of developing some mental health disorders, which include PTSD, depression, anxiety, substance abuse symptoms associated with traumatic events due to genetic variables. Also, in a study conducted in Calgary Canada among individuals who have experienced traumatic events, result showed that females are at high risk of developing PTSD symptoms than male [76]. This conclusion can be drawn on Nigerian women as studies have shown that women (of all cultural background) have "a generalized vulnerability" to PTSD [76].

Furthermore, recent research results have shown that associated with traumatic histories in African are substance abuse, risky sexual behaviors, and depression. Regarding depression among women victims of traumatic events, some Nigerian scholars have suggested "among victims who are still living with their perpetrators, high amounts of stress, fear and anxiety are commonly reported. Depression is also common, as victims are made to feel guilty for 'provoking' the abuse and are frequently subjected to intense criticism. It is reported that $60 \%$ of victims meet the diagnostic criteria for depression, either during or after" [6]. In addition, some studies have shown that traumatic experiences of any form experienced by women have psychological consequences 
which include: depressive symptoms, substance abuse, early sexual activity; alcohol, tobacco and drug abuse; multiple sexual partners; choosing abusive partners later in life; and lower rates of contraceptive and condom use $[23,27,36,39,78]$. It is also very common that these mental health disorders do have life-long effects on most Nigerian women. This is very dependent on a lot personal variables. However, this does not rule out the fact that most Nigerian women who have experienced any form traumatic events may have some or most of these mental health disorders.

In addition, many studies have associated traumatic events experienced by women to pregnancy-related issues and problems. For instance, some scholars have identified these issues as maternal issues that are unique to women, especially women who are pregnant when they experienced the traumatic event or events. Some of these pregnantrelated and maternal problems include "low maternal weight gain, miscarriage and stillbirth, and low-birth-weight babies" $[16,23,57,78]$. In another studies, it has been suggested that women who experienced any form of traumatic events during pregnancy are at high risk of the following: "lowbirth-weight infants, maternal death, and femicide" [29,30,34]. It is important to note that most; if not all pregnant Nigerian, women who have experienced one form of traumatic events share the same consequences.

Furthermore, effects of work-related sexual harassments among Nigerian women (which has its serious psychological and work environmental consequences) has been reported by many studies globally. For instance, in a recent study, it has been suggested that, "Currently, workplace harassment is a severe problem prevailing globally. Working people are exposed to general and sexual harassment at their workplaces. In spite of all measures to prevent sexual harassment, the issue is long lasting and never-ending. Globally, it is negatively affecting the physical and mental health of the working women" [49]. Scholars have also suggested that such experience (work harassment) has been categorized as one of the major ways women experience traumatic events. This form of traumatic event has been responsible for the development of some work related limitations on the part of women. For instance, studies have suggested the following as some of the chronic effects of sexual harassment traumatic events: poor work performance, lack of motivation, low tolerance and consideration for their patients, severe stress symptoms, adjustment disorders, and phobic and somatoform disorders $[48,49]$.

\section{Recommendations}

Based on the literature reviewed so far and exploration of traumatic experiences among Nigerian women, certain recommendations can be made. First, studies have shown that there are communal nature of the Nigerian culture and society. This is because Nigerian society has more interpersonal characteristics than individualistic characteristics. It is appropriate that professionals make use of these interpersonal elements of Nigerian culture to treat most Nigerian women who might have experienced one or more traumatic events.
Additionally, it is also important to note the effectiveness of some Western-oriented treatment approaches in treating trauma related symptoms. These approaches include Cognitivebehavioral therapy, Family Systems Therapy, Psychoanalytic Therapy, Person-Center Therapy, Reality Therapy and more. These approaches can be effectively used alone or in combination with traditional/Spiritual treatment approaches in Nigerian society.

\section{Conclusion}

In conclusion, some studies have also indicated that due to the aforementioned traumatic experiences endured by Nigerian women, it is very obvious that a lot of Nigerian women have not only suffered psychological, economic, social effects, but also have experienced the loss of basic human rights. This has been suggested to be the most crucial effects of traumatic events among Nigerian women. It is very unfortunate that the denial of basic fundamental human right has been embedded and supported most of the times by social norms and tradition of the Nigerian society.

This article has shown that trauma is a universal experience. However, the way in which trauma is interpreted, as well as the effects of trauma on an individual, are all influenced by the cultural lens through which the person views the event. Meaning that, its interpretation, prevention and treatment has to respect culture of the individual inflicted. Though, it has been found that women (of all cultural background) have "a generalized vulnerability" and that offspring's of individuals who have experienced traumatic events are at high risk of developing some mental health disorders, yet, non-western cultures have identified various symptoms and event-related triggers of traumatic experiences. Thus, women in Nigeria are exposed to the risk of being traumatized in addition to the workplace harassment negatively affecting the physical and mental health of the working women globally, to unique family norms and socio-cultural intricacies as highlighted. These have become barriers to the psychological well-being of Nigerian women through stress, resulting from traumatic and rapid changes of life events.

\section{References}

1. Abubakar S. Traumatic experiences of nigerian women: an archetypal representation in adichie"s purple hibiscus. IRA-International Journal of Management \& Social Sciences.2016; 4(3): 602-611. doi: 10.21013/jmss. v4.n3.p10

2. Acierno R, Resnick H, Kilpatrick DG, Saunders B, Best CL. Risk factors for rape, physical assault, and posttraumatic stress disorder in women: examination of differential multivariate relationships. Journal of Anxiety Disorder. 1999; 13(6): 541-63.

3. Agomoh O. Coping with widowhood.Vanguard Newspaper, 1987.

4. Aja-Okorie. Sexual harassment/victimization in nigeria universities: an impediment to effective university administration. Journal of Harmonized Research in Management. 2014; 1(1): 18-29.

5. Akubor ED. The role of religion in nigerian building and the Nigerian situation: a historical perspective. 2009. 
6. Alokan FB. Doemstic violence against women: a family menace. First Annula International Interdisciplinary Conference. AICC. 2013; 24-26April, Azores, Portugal.

7. American Psychiatric Association (2013). Diagnostic and Statistical Manual of Mental Disorders, 5th ed . Washington, DC: American Psychiatric Association.

8. Amowitz LL, Reis C, Lyons KH, Vann B, Mansaray B, Akinsulure-Smith $A M$. Prevalence of war-related sexual violence and other human rights abuses among internally displaced persons in Sierra Leone. JAMA.2002; 287: 513-21.

9. Austin J, Guy S, Lee-Jones L, McGinn T, Schlecht J. Reproductive health:A right for refugees and internally displaced persons. Reprod Health Matters. 2008; 16: 10-21. doi: 10.1016/S0968-8080(08)31351-2

10. Behrendt A, Moritz S. Posttraumatic stress disorder and memory problems after female genital mutilation. Am J Psychiatry. 2005; 162(5): 1000-2. doi: 10.1176/appi.ajp.162.5.1000

11. Bergen RK. Wife Rape: Understanding the Response of Survivors and Service Providers. Sage Publications Inc. 1996. doi: 10.4135/9781483327624

12. Brahm E. Trauma healing. Retrieved from Beyonditractability. org. 2004.

13. Briere J \& Scott C. Principles of Trauma Therapy: A Guide to Symptoms, Evaluation, and Treatment 1st Edition. SAGE. 2006.

14. Burrage H. Eradicating female genital mutilation: a UK perspective. 2015. Ashgate Publishing Limited. Retrieved online on November 27, 2017.

15. Buse NA, Burker $E$, \& Bernacchio C. Cultural variation in resilience as a response to traumatic experience. Journal of Rehabilitation, 2013; 79(2): 15-23.

16. Campbell JC. Health consequences of intimate partner violence. Lancet. 2002; 359(9314): 1331-36. doi: 10.1016/\$0140-6736(02)08336-8

17. Connor KM, Davidson JR, Lee L. Spirituality, resilience, and anger in survivors of violent trauma: A community survey. Journal of Traumatic Stress. 2003; 16: 487-494.

18. Chung S. Telephone interview with $\operatorname{Dr}$ Brenda Kelly. 4 December. Retrieved online on November 27, 2017. 2015.

19. Danielson $C K$, Amstadter $A B$, Dangelmaier RE, Resnick $H S$, Saunders $B E$, Kilpatrick DG. Trauma-related risk factors for substance abuse among male versus female young adults. Journal of Addictive Behavior. 2009; 34(4): 395-9. doi: 10.1016/j.addbeh.2008.11.009

20. Oluwole DA. Patterns of stress, social support and mental health among Nigerian women

21. Davis JL, DeMaio CM, \& Fricker-Elhai AE. Sexual assault prevention targeting involvement in risky behaviors: A three-month follow-up. Journal of Trauma Practice. 2004; 3(4); 1-22.

22. De Wet A. Sexual Harassment of Learners in Secondary Schools: An Education Law Perspective (Degree Philosophiae Doctor in Education Law at Potchefstroom Campus of the North-West University). 2010.

23. Dube SR, Anda RF, Whitfield CL, Brown DW, Felitti VJ, Dong M, and Giles WH. Long-term consequences of childhood sexual abuse by gender of victim. American Journal of Preventive Medicine. 2005; 28(5): 430-38. doi: 10.1016/j.amepre.2005.01.015

24. Dziech BW, Weiner $L$. The lecherous professor: sexual harassment on campus. 1994; $2^{\text {nd }}$ edtion University of Illinois Press

25. Elements Behavioural Health, PSTD trauma treatment.2011.

26. Elnashar A, Abdelhady R. The impact of female genital cutting on health of newly married women. International Journal of Gynecology \& Obstetrics. 2007; 97(3): 238-244. doi: 10.1016/j.ijgo.2007.03.008

27. Equality Now and City University London 'Female Genital Mutilation in England and Wales: Updated statistical estimates of the numbers of affected women living in England and Wales and girls at risk', Interim report on provisional estimates. 2014.

28. Faul M. (2015). Nigerian Women Rescued from Boko Haram Face Trauma andStigma. CTV News on Sunda, May 10, 2015. Retrieved online on November, 27, 2017.
29. Fauveau V, Koenig MA, Chakraborty J, and Chowdhury Al. Causes of maternal mortality in rural Bangladesh, 1976-85. Bulletin of the World Health Organization. 1988; 66(5): 643-51.

30. Ganatra BR, Coyaji KJ, Rao VN. Too far, too little, too late: a communitybased case-control study of maternal mortality in rural west Maharashtra, India. Bulletin of the World Health Organization. 1998; 76(6): 591-98.

31. Getanda EM, Papadopoulos C, Evans H. The mental health, quality of life and life satisfaction of internally displaced persons living in Nakuru County, Kenya. BMC Public Health. 2015; 15: 755. doi: 10.1186/s12889-015-2085-7

32. Glatz C. Infertility leads to trauma and broken marriages, says Nigerian. bishop. Building the kingdom in the classroom. A school chaplain's diary. 2015.

33. Hill C, Silva E. Drawing the line: sexual harassment on campus. 2005.

34. Horon IL, Cheng D. Enhanced surveillance for pregnancy-associated mortality - Maryland, 1993-1998. Journal of the American Medical Association. 2001; 285(11): 1455-59.

35. Improving Trauma Care Act of 2014, H.R. 3548. (2014).

36. Jejeebhoy S, Shah I, and Thapa S. Sex without consent: young people in developing countries. London, Zed Books. 2005.

37. Jewkes R, Sen P, and Garcia-Moreno C. Sexual violence. In: Krug EG et al., eds. World report on violence and health. Geneva. World Health Organization. 2002; 147-182.

38. Jobson L, O'Kearney R. Cultural differences in personal identity in posttraumatic stress disorder. Journal of Clinical Psychology. 2006; 47(1): 95109. doi: $10.1348 / 014466507 \times 235953$

39. Johnson MP, Leone JM. The differential effects of intimate terrorism and situational couple violence: findings from the national violence against women survey. Journal of Family Issues. 2005; 26(3): 322-49.

40. Keel A. Re: Female Genital Mutilation (Letter to Health Professionals in Scotland. 2014.

41. Lawrence RJ. PTSD and high-risk behaviours in trauma survivors. 2012.

42. Lee $D$, \&Young K. Post-traumatic stress disorder: Diagnostic issues and epidemiology in adult survivors of traumatic events. International Review of Psychiatry. 2001; 13: 150-158. doi: 10.1080/09540260120074000

43. Mann S, Jones RG. The expression and suppression of emotion in intraOrganizational communications Paper presented at the Annual Conference of the Occupational Psychology Division of the British Psychological Society. 1996.

44. Marama N, Yusuf U, Ojeme V. The Vanguard Newspaer $18^{\text {th }} 2015$.

45. Martin SL.Pregnancy-associated violent deaths: the role of intimate partner violence. Trauma, Violence \& Abuse. 2007; 135-48. doi: $10.1177 / 1524838007301223$

46. Memon A. 'Female genital cutting: a community based approach to behavior change', Working Paper. 2014

47. Merriam-Webster Dictionary

48. Mojoyinola JK. Effects of job stress on health, personal and work behavior of nurses in public hospitals in Ibadan Metropolis, Nigeria. Ethno-Medicine. 2008; 2:143-8. doi: 10.1080/09735070.2008.11886326

49. Mushtaq M, Sultana S, and Imtiaz I. The Trauma of Sexual Harassment and its Mental Health Consequences Among Nurses. Journal of the College of Physicians and Surgeons Pakistan. 2015; 25(9): 675-79. doi: 09.2015/JCPSP. 675679

50. Mustapha AA, Adebiyi GY, Yusuf AJ, Abdullahi JR, Lawal B. Psychosocial morbidity in women attending an infertility clinic in Northwestern Nigeria: 'It's the worst misfortune of a woman'. Journal of Gynecology and Obstetrics. 2015; 3(1): 6-12.

51. Nsofor. Inside a Nigerian lidp camp - a public health perspective AfricaEventsHealthNigeria. 2015.

52. Obindo TJ. Prevalence of Violence and Symptoms of Post-Traumatic Stress Disorder among victims of Ethno-Religious conflict in Jos, Nigeria. Open Journal of Psychiatry. 2014; 18(1). 
53. Oluwole IO, Obadeji A, Dada UM. Burden of stigma among relatives of Nigerian patients living with epilepsy. Journal of Health Research and Reviews. 2015; 2(2): 61-65. doi: 10.4103/2394-2010.160913

54. Osemene M. (1989, 27th July) Oral Interview, Held at Agbo. Mike Osemene Isa Deltan-Igbo man working in Issele-Uku Dio 48 years old.

55. Owoaje ET, Uchendu OC, Ajayi TO, Cadmus EO. Review of the health problems of the internally displaced persons in Africa. Niger Postgrad Med J. 2016; 23(4):161-171. doi: 10.4103/1117.

56. Perren-Klingler $\mathrm{G}$. The Integration of Traumatic Experiences in a Cultural Context. Institute Psychotrauma Schweiz. 2015.

57. Pallitto $C$. Domestic violence and maternal, infant, and reproductive health: a critical review of the literature. Pan-American Health Organization. 2004. doi: 10.4172/2325-9795.1000208

58. Rishipal. A Blocked Emotions; Mental Suffocation, Emotional Ventilation; Powerful Living. International Journal of Marketing, Financial Services \& Management Research. 2013; 2277- 3622.

59. Robert F. Death, Grief and social recuperation. Omega: an International Journal psychology, Gical study of dying death, bereavement suicide and other lethal behaviours. Detrist Miniesola: University Press.1970.

60. Robinson $\mathrm{KH}$. Reinforcing hegemonic masculinities through sexual harassment: issuesof identity, power and popularity in secondary schools. Gender and Education. 2005; 17(1): 19-37. doi: 10.1080/0954025042000301285

61. Saladin ME, Brady KT, Dansky BS, Kilpatrick DG. Understanding comorbidity between PTSD and substance use disorders: two preliminary investigations. Journal of Addictive Behaviors. 1995; 20(5): 643-55. doi: 10.1016/0306-4603(95)00024-7

62. Saxon L, Makhashvili N, Chikovani I, Seguin M, McKee M, Patel V. Copingstrategies and mental health outcomes of conflict-affected persons in the Republic of Georgia. Epidemiology and Psychiatric Sciences. 2016; 26(3): 276-286. doi: 10.10171S2045796016000019

63. Sheikh TL, Mohammed A, Agunbiade S, Ike J, Ebiti WN, Adekeye O. Psycho-Trauma, Psychosocial Adjustment, and Symptomatic PostTraumatic Stress Disorder among Internally Displaced Persons in Kaduna, Northwestern Nigeria. Front Psychiatry. 2014; 5: 127. doi: 10.3389/fpsyt.2014.00127

64. Smigelsky M, Aten J, Gerberich S, et al. (2014). Trauma in sub-Saharan Africa: review of cost, estimation methods, and interventions. International Journal of Emergency Mental Health. 2014; 16(2): 354-365.

65. Smit D, Du Plessis V. Sexual harassment in education sector. Potchefsroom Electronic Law Journal. PER/PEL. 2011; 14(6). doi: 10.4314/pelj.v14i6.6
66. Stark L, Roberts L, Wheaton W, Acham A, Boothby N, Ager A. Measuring violence against women amidst war and displacement in Northern uganda using the "neighbourhood method". J Epidemiol Community Health. 2016; 64(12):1056-61. doi: 10.1136/jech.2009.093799

67. Substance Abuse and Mental Health Services Administration (2014). SAMHSA's concept of trauma and guidance for a trauma-informed approach. Rockville, MD: SAMHSA's Trauma and Justice Strategic Initiative., p.7

68. Taskforce on the health aspects of violence against women and children. Responding to violence against women and children - the role of the NHS. London, Department of Health, 2010.

69. Uadia PO, Emokpae AM. Male infertility in Nigeria: a neglected reproductive health issue requiring attention. Journal of Basic and Clinical reproductive sciences-official publication of society of reproductive Biologists of Nigeria. 2015; 4(2). doi: 10.4103/2278-960X.161042

70. United Nations General Assembly. In-depth study on all forms of violence against women. New York, NY, United Nations, 2006.

71. Ushe MN. Between Continunity and Change: Comparison of Tiv and Christian concept of Death and Burial Rites. An Unpublished PhD dissertation submitted to the Department of Religious Studies University of Jos.2005.

72. Ushe MU. The plights of widow in Nigeria: the paradox for traditional counseling of the bereaved. Journal of Research in Education and Society. 2011; 2(3)

73. Vasile C. An analysis of psychological trauma interventions. Journal of Social and Behavioral Science. 2014; 127: 781-785. doi: 10.1016/j. sbspro.2014.03.354

74. Vitanza S. Vogal LC, Marshall LL. Distress and symptoms of posttraumatic stress disorder in abused women. Violence and Victim. 1995; 10(1): 23-24.

75. Vloeberghs $E$, Knipscheer J, van $\operatorname{der}$ Kwaak $A$, van den Muijsenbergh M.Coping and chronic psychosocial consequences of female genital mutilation in the Netherlands. Ethnicity \& Health. 2012; 17(6): 677-695. doi: $10.1080 / 13557858.2013 .771148$

76. Voges MA, DMR. Risk and resiliency factors in post-traumatic stress disorders. Annals of General Hospital Psychiatry. 2003.

77. Whitehorn J, Ayonrinde $\mathrm{O}$, Maingay S. Female genital mutilation: Cultural and psychological implications. Sexual and Relationship Therapy. 2002; 17(2): 161-170. doi: 10.1080/14681990220121275

78. WHO, World Health Organisation. WHO laboratory manual for examination \& processing of human semen and sperm-cervical mucus interaction. $3^{\text {rd }}$ edition New York; Cambridge University Press; 1992. 